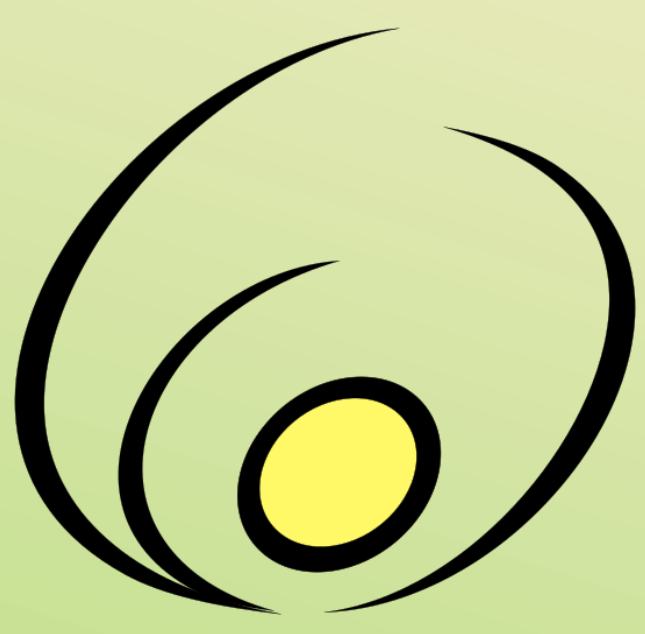

Fórum de

\section{Pró-Reitores}

de Extensão

das Instituições

Públicas de

\section{Educação Superior}

Brasileiras
Open access $\delta$ free available online

Revista Brasileira de Extensão Universitária

v. 9, n. 1, p. 47-56 jan.- abr. 2018 e-ISSN 2358-0399

DOI: https://doi.org/10.24317/2358-0399.2018v9i1.6838

originais recebidos em 18 de setembro de 2017

aceito para publicação em 19 de março de 2018

\title{
Conservação in vitro da biodiversidade vegetal: abordagem no ensino médio
}

Resumo: As plantas constituem a base dos ecossistemas e a necessidade de conservar a biodiversidade é imprescindível para a sociedade. O objetivo deste projeto foi conscientizar os alunos de uma escola pública de ensino médio do Rio de Janeiro desta realidade, gerando oportunidade para graduandos e pósgraduandos transmitirem conceitos de biotecnologia aplicada à conservação de plantas. A metodologia consistiu de palestras, documentários em vídeo e visita técnica aos laboratórios do Núcleo de Biotecnologia Vegetal da Universidade do Estado do Rio de Janeiro, onde os alunos acompanharam a produção e a conservação de plantas in vitro. A avaliação baseou-se na frequência e na participação, além da comparação das respostas a um questionário aplicado no início e ao final do projeto. Foi detectada uma grande variação entre as turmas, tanto na frequência (41-68\%), quanto no percentual de acertos nos questionários, inicial (42-57\%) e final (53-68\%). Contudo, todas as turmas avaliadas apresentaram maior rendimento após a participação no projeto, indicando um efeito positivo nas questões específicas de Biotecnologia e sua aplicação na conservação da Biodiversidade.

Palavras-chave: Desenvolvimento Sustentável, Cultura In Vitro, Ensino de Biologia, Biotecnologia Vegetal

\footnotetext{
1 Doutoranda do Programa de Pós-graduação em Biologia Vegetal, Universidade do Estado do Rio de Janeiro - UERJ. belabiouerj@gmail.com

2 Bióloga do Núcleo de Biotecnologia Vegetal, UERJ biabiouerj@gmail.com

3 Doutoranda do Programa de Pós-graduação em Biologia Vegetal, UERJ. mineapettinelli@gmail.com

4 Bióloga do Núcleo de Biotecnologia Vegetal, UERJ renatagarci@gmail.com

5 Professora docente I no Colégio Estadual João Alfredo e Bióloga da Universidade do Estado do Rio de Janeiro crsilva@uerj.br

6 Professora adjunta do Departamento de Biologia Vegetal e pesquisadora do Núcleo de Biotecnologia Vegetal - Instituto de Biologia Roberto Alcantara Gomes, UERJ. gagliard@uerj.br (autora para correspondência)
} 


\title{
In vitro conservation of plant biodiversity: approach in high school
}

\begin{abstract}
Plants constitute the base of ecosystems and the need to conserve biodiversity is indispensable for society. The aim of this project was to raise awareness among students of a public high school in Rio de Janeiro, creating opportunity for undergraduate and graduate students to transmit concepts of biotechnology applied to plants' conservation. The methodology consisted of lectures, videos documentaries and a technical visit to laboratories of the Plant Biotechnology Center of the Rio de Janeiro State University where students saw in vitro production and conservation of plants. The evaluation was based on the attendance and participation, as well as the comparison of the answers to questionnaires applied in the beginning and the end of the project. A large variation in the results between the classes was detected both in the frequency (41-68\%) and in the percentage of correct answers in the initial (42-57\%) and final (53-68\%) questionnaires. However, all evaluated classes showed higher performance after participating in the project, indicating a positive effect on specific issues of biotechnology and its application in biodiversity conservation.
\end{abstract}

Keywords: Sustainable Development, In Vitro Culture, Biology Teaching, Plant Biotechnology

\section{Conservación in vitro de biodiversidad vegetal: enfoque en la enseñanza media}

Resumen: Las plantas constituyen la base de los ecosistemas y la necesidad de conservar la biodiversidad es imprescindible para la sociedad. El objetivo de este proyecto fue concientizar a los alumnos de la enseñanza media pública de esta realidad, generando oportunidad para graduandos y post-graduandos transmitir conceptos de biotecnología aplicada a la conservación de plantas. La metodología consistió de conferencias, vídeos y visita técnica a los laboratorios del Núcleo de Biotecnología Vegetal de la Universidad del Estado de Río de Janeiro, donde los alumnos acompañaron la producción y la conservación de plantas in vitro. La evaluación se basó en la comparación de las respuestas a un cuestionario aplicado al principio y al final del proyecto. Se detectó una gran variación en los resultados entre las clases, tanto en la frecuencia (41-68\%), como en el porcentaje de aciertos en los cuestionarios inicial (42-57\%) y final (53-68\%). Sin embargo, todas las clases evaluadas presentaron mayor rendimiento después de la aplicación en el proyecto, indicando un efecto positivo en las cuestiones específicas de Biotecnología y su aplicación en la conservación de la Biodiversidad.

Palabras-clave: Desarrollo Sostenible, Cultivo In Vitro, Enseñanza de Biología, Biotecnología Vegetal

\section{Introdução}

Biodiversidade ou diversidade biológica são termos que têm o mesmo significado e são usados para definir a variedade de formas de vida desenvolvidas ao longo do processo evolutivo (METZGER; CASATI, 2006). Atualmente, a extinção de espécies, como consequência da degradação ambiental, chegou a níveis críticos e o tema passou a ser intensamente discutido pela sociedade. Além da questão ambiental, a biodiversidade é responsável pela segurança alimentar e econômica, na medida em que fornece os recursos genéticos e biológicos que sustentam a agricultura, a indústria em geral e a produção de energia (RIBEIRO; RODRIGUES, 2006).

Neste contexto, o estudo do tema "Biodiversidade" na educação básica propõe fomentar nos estudantes a consciência do real valor dos recursos naturais, embasando uma postura responsável em relação aos problemas ambientais atuais, com o propósito de buscar soluções sustentáveis para o desenvolvimento econômico futuro. Dentre as muitas formas de conservar a biodiversidade, a biotecnologia vegetal, com suas diversas técnicas, surge como ferramenta aliada, que facilita a manipulação das plantas para obtenção de processos ou produtos de interesse, com aplicação em diferentes áreas, como o melhoramento e a produção de metabólitos de interesse econômico (CANHOTO, 2010). Assim, a cultura de tecidos vegetais (CTV) é a alternativa biotecnológica mais adequada para a produção e a conservação de espécies que não são produzidas por agricultura convencional e cuja exploração predatória vem causando erosão genética e extinção em ritmo acelerado.

Os Parâmetros Curriculares Nacionais para o ensino médio (PCNEM) prevêem a apresentação de alguns temas da biotecnologia vegetal, como a obtenção de plantas geneticamente transformadas, nas aulas de biologia vegetal. Entretanto, esta área agrega diferentes disciplinas, como a fisiologia, a anatomia, a taxonomia, a organografia, a evolução, a biologia celular e a genética, entre outras, evidenciando a complexidade multidisciplinar para a compreensão da biologia das 
plantas, organismos profundamente relacionados ao cotidiano de nossa sociedade. Como agravante, os livros didáticos de Biologia, usados como eixo condutor de conteúdo na maioria das escolas, são desatualizados em relação aos temas de biotecnologia vegetal (XAVIER et al., 2006). Consequentemente, estes temas são abordados de forma superficial, carecendo da fundamentação necessária para uma postura crítica em relação à aplicação destas práticas.

Apesar da importância da biologia vegetal para a compreensão das diferentes questões ambientais e alimentares enfrentadas pela civilização, seu estudo não tem despertado o interesse dos alunos ingressantes nos cursos de Ciências Biológicas. Esta situação tem sido observada em muitas instituições e em diferentes níveis (PEDRANCINI et al., 2007, SILVA; GHILARDILOPES, 2014). Grande parte dos alunos ingressantes carece de conhecimentos básicos, que deveriam trazer do ensino médio, dificultando sua participação e posicionamento ativo em projetos de conservação.

Embora as razões para explicar este desinteresse não sejam muito claras, algumas hipóteses vêm sendo discutidas, dentre as quais a fragmentação do conteúdo entre os diferentes temas e a concentração em morfologia e classificação (SANO, 2004), limitando o ensino à memorização da nomenclatura, sem vínculo com a função estrutural (FREITAS et al., 2009, SILVA; MORAES, 2011, MACHADO, 2014). Agravando esta situação, o formato tradicional de aulas teóricas, sem o apoio de aulas práticas e sem a utilização de recursos e abordagens alternativas para o ensino da biologia das plantas, não favorece a compreensão de processos biológicos dinâmicos. A proposta de estudar a conservação de recursos genéticos vegetais usando-se diferentes abordagens pode estimular o interesse dos alunos pelo tema e ainda contribuir para a formação de opinião voltada para o desenvolvimento sustentável.

O objetivo deste projeto foi introduzir, em uma escola de ensino médio da rede pública de ensino do Estado do Rio de Janeiro, os conceitos e fundamentos da conservação de espécies de interesse econômico, estudadas no Núcleo de Biotecnologia Vegetal da Universidade do Estado do Rio de Janeiro (NBV/UERJ). Como objetivos específicos, o trabalho visou: (i) conscientizar os estudantes da importância da biodiversidade vegetal para a humanidade; (ii) enfatizar a urgência de produzir e conservar plantas através de tecnologias sustentáveis; (iii) apresentar a biotecnologia vegetal como ferramenta complementar na conservação de plantas.

\section{Metodologia}

O presente trabalho está inserido em um projeto de extensão cadastrado na Universidade do Estado do Rio de Janeiro - UERJ, e foi desenvolvido em um colégio estadual, situado em Vila Isabel, no município do Rio de Janeiro. A instituição foi selecionada em função de sua proximidade ao campus universitário, eliminando a necessidade de gasto financeiro com transporte para o deslocamento dos participantes, entre as duas instituições. Este projeto foi aplicado durante os meses de setembro e outubro de 2015, em cinco turmas da terceira série do ensino médio do turno da manhã, em horário das aulas de biologia, ocupando uma carga horária de cinco horas por turma, distribuídas em quatro dias diferentes e abrangendo um total de 228 alunos.

A metodologia consistiu de três palestras, ministradas por alunos do Programa de Pós-Graduação em Biologia Vegetal da UERJ, que abordaram temas básicos de biologia vegetal (células, produção de energia e biodiversidade), além de um conteúdo específico sobre a biotecnologia vegetal (regeneração e cultura de tecidos) e sua importância na conservação de espécies nativas de interesse econômico, com ênfase em plantas medicinais. Alunos do curso de graduação em Ciências Biológicas da UERJ também participaram das demais atividades desenvolvidas ao longo do projeto. Além das palestras, foram apresentados dois documentários em vídeo, um sobre o desenvolvimento vegetal em geral ("A vida secreta das plantas"), produzido pela British Broadcasting Corporation e outro sobre a produção de alimentos ("Benefícios da Biotecnologia da Agricultura"), produzido pela Empresa Brasileira de Pesquisa Agropecuária - EMBRAPA. As palestras e documentários foram atividades executadas na própria escola, usando a infraestrutura disponível. Além disso, uma visita técnica ao Núcleo de Biotecnologia Vegetal (NBV) da UERJ foi oferecida a dez alunos, selecionados em cada turma, em função de seu interesse durante o projeto. Durante a visita, os alunos tiveram a oportunidade de acompanhar todo o processo de micropropagação, desde a descontaminação de material vegetal, passando pelo cultivo em meios específicos para multiplicação, até a aclimatização das plantas produzidas, recebendo ao final, uma muda in vitro de espécie nativa, com informações e instruções para sua manutenção. Durante a atividade, além dos laboratórios e câmaras de crescimento de plantas, foram apresentados os equipamentos usados para produção de extratos vegetais, análises fitoquímicas e genéticas.

Um questionário foi aplicado no início e ao final do projeto (Anexo 1) contendo dez questões de múltipla escolha com cinco alternativas cada (sendo apenas uma correta) e uma questão com duas alternativas (sim e não) e possibilidade de justificativa aberta. As justificativas apresentadas foram analisadas com base em categorias extraídas das respostas (ROCHA SILVA et al., 2005). As questões de 1 a 5 tiveram como base os temas de biologia vegetal, fundamentais à compreensão das técnicas biotecnológicas apresentadas durante o projeto; as questões 6 a 10 abordaram o conteúdo de biotecnologia vegetal e a questão discursiva (11) abordou a importância da biotecnologia vegetal no mundo atual.

A avaliação geral de desempenho dos alunos baseou-se na frequência e participação nas atividades e na comparação das respostas aos questionários, aplicado no início e ao final do projeto. Os temas abordados nas diversas atividades e avaliados no questionário são listados no Quadro 1. 


\section{Análise estatística}

A influência do projeto na assimilação dos temas propostos foi avaliada pelo teste estatístico de McNemar para significância de mudanças, considerando-se $p<0,02$ (SIEGEL; CASTELAN-JÚNIOR, 2006). Para cada questão, as respostas dos alunos foram sintetizadas em acertos ou erros. Os alunos que mantiveram a resposta nos questionários inicial e final (acerto ou erro em ambos) foram contabilizados, assim como os alunos que apresentaram respostas diferentes, acertando apenas no questionário inicial ou no final. Dessa forma, o teste avaliou a significância de mudanças positivas (erro no questionário inicial e acerto no final), levando em consideração as mudanças negativas (acerto no questionário inicial e erro no final) e a não ocorrência de mudanças. Os cálculos foram realizados para cada questão utilizando a ferramenta online QuickCalcs (GraphPad Software, La Jolla, Califórnia, USA).

O rendimento dos alunos foi calculado pela porcentagem de acertos nas questões objetivas (1 a 10). O desempenho entre as turmas foi definido pela comparação entre o rendimento médio de cada turma nos questionários aplicados no início e ao final do projeto. As diferenças entre as turmas foram analisadas pelo teste $t$ pareado $(p<0,05)$ (GraphPad Prism versão 6.00 para Windows, GraphPad Software, La Jolla, Califórnia, USA).

$\mathrm{Na}$ análise de desempenho através dos questionários, verificou-se grande variação no rendimento entre os alunos das turmas participantes, com alguns destaques individuais. A frequência geral dos alunos respondentes foi de $74 \%$ no questionário inicial e de $63 \%$ no final. As análises foram realizadas apenas com os dados dos alunos que participaram de ambos os questionários, totalizando 57\% dos alunos (Tabela 1). Em relação ao rendimento, a maioria das turmas apresentou notas mais altas no questionário final, em comparação ao inicial (Figura 1A). De um modo geral, observou-se um número maior de acertos no questionário final nas questões objetivas, tanto em biologia vegetal (1 a 5) (Figura 1B), quanto em biotecnologia vegetal (6 a 10) (Figura 1C). Contudo, diferenças estatisticamente significativas foram observadas apenas nas questões 4, 6 e 8. Este resultado indica que houve acréscimo no aprendizado acerca da estrutura da célula eucariótica (questão 4), conteúdo presente no currículo mínimo do ensino médio. Além disso, constatou-se a assimilação satisfatória de conceitos novos de biotecnologia vegetal, como a totipotência celular vegetal e a micropropagação (questões 6 e 8, respectivamente).

Quadro 1. Temas de Biologia Vegetal avaliados no questionário.

\begin{tabular}{|c|c|c|}
\hline $\begin{array}{l}\text { Questão } \\
\left(n^{\circ}\right)\end{array}$ & Tema & Objetivo \\
\hline 1 & Biodiversidade & $\begin{array}{c}\text { Determinar se os alunos são capazes de considerar animais e vegetais como } \\
\text { componentes da biodiversidade }\end{array}$ \\
\hline 2 & Reinos Animal e Vegetal & $\begin{array}{l}\text { Avaliar se os alunos consideram os animais e os vegetais como seres vivos e } \\
\text { se são capazes de diferenciar os reinos }\end{array}$ \\
\hline 3 & Células Eucarióticas & $\begin{array}{c}\text { Determinar o conhecimento dos alunos sobre a organização da célula } \\
\text { eucariótica }\end{array}$ \\
\hline 4 & Célula Vegetal & $\begin{array}{c}\text { Examinar se os alunos conhecem a célula vegetal e suas principais } \\
\text { estruturas }\end{array}$ \\
\hline 5 & Fotossíntese & $\begin{array}{l}\text { Determinar o conhecimento dos alunos sobre a importância do processo de } \\
\text { fotossíntese }\end{array}$ \\
\hline 6 & Totipotência & $\begin{array}{c}\text { Determinar como os alunos apreenderam o conceito de totipotência e se são } \\
\text { capazes de identificar as células totipotentes em plantas }\end{array}$ \\
\hline 7 & Clonagem & Avaliar o conhecimento adquirido pelos alunos sobre aspectos da clonagem \\
\hline 8 & Micropropagação & Avaliar a compreensão dos alunos sobre a micropropagação \\
\hline 9 & $\begin{array}{l}\text { Cultura de Tecidos } \\
\text { Vegetais }\end{array}$ & $\begin{array}{c}\text { Verificar se os alunos entenderam as aplicações da técnica de cultura de } \\
\text { tecidos vegetais }\end{array}$ \\
\hline 10 & Biotecnologia Vegetal & $\begin{array}{c}\text { Determinar a opinião dos alunos sobre a aplicação da biotecnologia vegetal } \\
\text { na proteção da biodiversidade }\end{array}$ \\
\hline 11 & $\begin{array}{l}\text { Biotecnologia Vegetal } \\
\text { (discursiva) }\end{array}$ & $\begin{array}{c}\text { Avaliar a capacidade dos alunos de justificar a importância da biotecnologia } \\
\text { vegetal para a humanidade }\end{array}$ \\
\hline
\end{tabular}


Tabela 1. Frequência de alunos respondentes aos questionários e posicionamento favorável à importância da biotecnologia vegetal na questão discursiva $(n=228)$

\begin{tabular}{|c|c|c|c|c|c|}
\hline \multirow[b]{2}{*}{ Turma } & \multicolumn{2}{|c|}{ Questionário inicial } & \multicolumn{2}{|c|}{ Questionário final } & \multirow{2}{*}{$\begin{array}{c}\text { Frequência em } \\
\text { ambos os } \\
\text { questionários } \\
(\%)\end{array}$} \\
\hline & $\begin{array}{l}\text { Frequência } \\
\quad(\%)\end{array}$ & $\begin{array}{c}\text { Sim na questão } \\
11(\%)\end{array}$ & $\begin{array}{l}\text { Frequência } \\
\quad(\%)\end{array}$ & $\begin{array}{c}\text { Sim na questão } \\
11(\%)\end{array}$ & \\
\hline 3001 & 68 & 60 & 73 & 80 & 68 \\
\hline 3002 & 80 & 31 & 60 & 54 & 68 \\
\hline 3004 & 64 & 33 & 52 & 33 & 41 \\
\hline 3005 & 73 & 54 & 65 & 65 & 54 \\
\hline 3006 & 85 & 59 & 66 & 76 & 64 \\
\hline Média & 74 & 47 & 63 & 62 & 57 \\
\hline
\end{tabular}

$\mathrm{Na}$ questão 11, observou-se um aumento geral do percentual de alunos que declararam reconhecer a importância da biotecnologia vegetal para a humanidade, com exceção da turma 3004 (Tabela 1). Considerando as demais turmas, este valor foi, em média, de $47 \%$ no questionário inicial e $62 \%$ no final. Dentre as justificativas apresentadas pelos alunos, a proteção de espécies ameaçadas de extinção foi a mais citada em ambos os questionários. Além disso, algumas respostas foram bastante específicas, como "obter produtos úteis", com a citação de várias aplicações com impacto direto na sociedade (Figura 2).

\section{Discussão}

Este trabalho apresentou a proposta de introduzir conceitos de biotecnologia vegetal em algumas turmas de um colégio de ensino médio da rede pública, através de atividades dinâmicas, ao final das quais os alunos puderam acompanhar todas as etapas de produção de plantas in vitro. Durante a aplicação do projeto, foi enfatizada a utilização de técnicas biotecnológicas para a conservação da biodiversidade vegetal.

Visando facilitar a compreensão, foi realizado um reforço de conteúdos relativos a temas constantes nos PCNEM e nas Orientações Educacionais Complementares aos Parâmetros Curriculares Nacionais $(\mathrm{PCN}+)$ vigentes para o nível médio da rede pública estadual, tais como "diversidade dos seres vivos", "transformações essenciais à vida", "manutenção dos sistemas multicelulares", além de "humanidade e ambiente" e "ecossistemas e biotecnologia" (BRASIL, 2002, 2013).

Apesar de representar uma ação norteadora, o PCNEM não soluciona todas as dificuldades da educação básica pública. Com um extenso conteúdo, condensado em três anos letivos, os alunos apresentam deficiências na interpretação dos textos, impedindo a proficiência em matérias básicas (FAJARDO, 2012). Contornar estas dificuldades individualmente, em médio prazo, depende diretamente do aspecto motivacional do tema e da forma de apresentá-lo. Neste projeto, a substituição das aulas teóricas convencionais por palestras e documentários, apresentados por jovens universitários e recém-formados com interesse específico no tema, que desenvolvem seus trabalhos de conclusão de curso ou projetos de pósgraduação, provavelmente foi um fator positivo para a compreensão dos conteúdos. Apesar disso, os resultados foram aquém das expectativas em relação ao impacto do projeto, já que diferenças significativas foram detectadas apenas em três das 10 questões objetivas. Várias considerações poderiam explicar esse resultado e devem ser discutidas.

A participação dos alunos no projeto sofreu influência direta de atividades concomitantes, programadas por outras disciplinas no colégio, acarretando uma diminuição da participação dos alunos no questionário final $(11 \%$ de redução entre o questionário inicial e o final). Este dado indica que, para que ocorra ensinoaprendizagem, o trabalho dos docentes de diferentes disciplinas deve ser integrado, sem risco de superposição (QUINTINO; ROSA, 2005).

Os resultados individuais dos alunos demonstraram grande variação entre as turmas e mesmo entre alunos da mesma turma, provavelmente em decorrência da distribuição aleatória, sem critérios para uniformização dos grupos. Em relação ao questionário, a análise das questões objetivas levou em consideração o aumento de acertos ou erros nos questionários finais em comparação aos iniciais, de cada aluno e em cada questão. Observouse pequena parcela de alunos com rendimento negativo em algumas questões. Apesar de muitos fatores contribuírem para a ocorrência deste fenômeno, deve-se ressaltar a confusão, por parte de alunos desmotivados, sobre um tema que deveriam conhecer. Além disso, a falta de interesse no projeto também pode induzi-los a marcar respostas aleatórias e a copiar as respostas dos colegas. 
52 | Sousa, I. B. de et al.

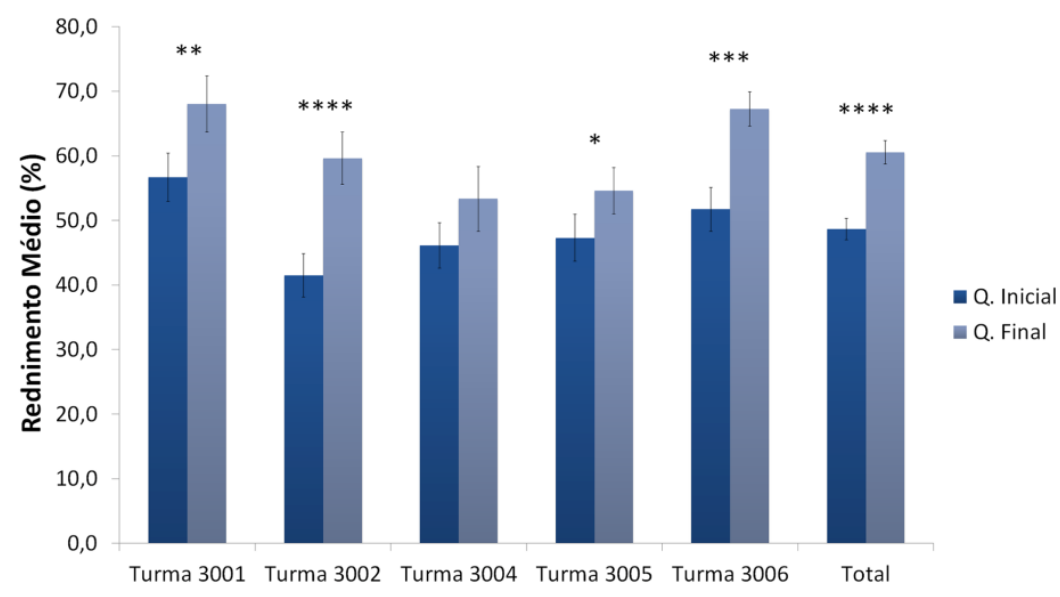

A.

Turma 3001 Turma 3002 Turma 3004 Turma 3005 Turma 3006 Total

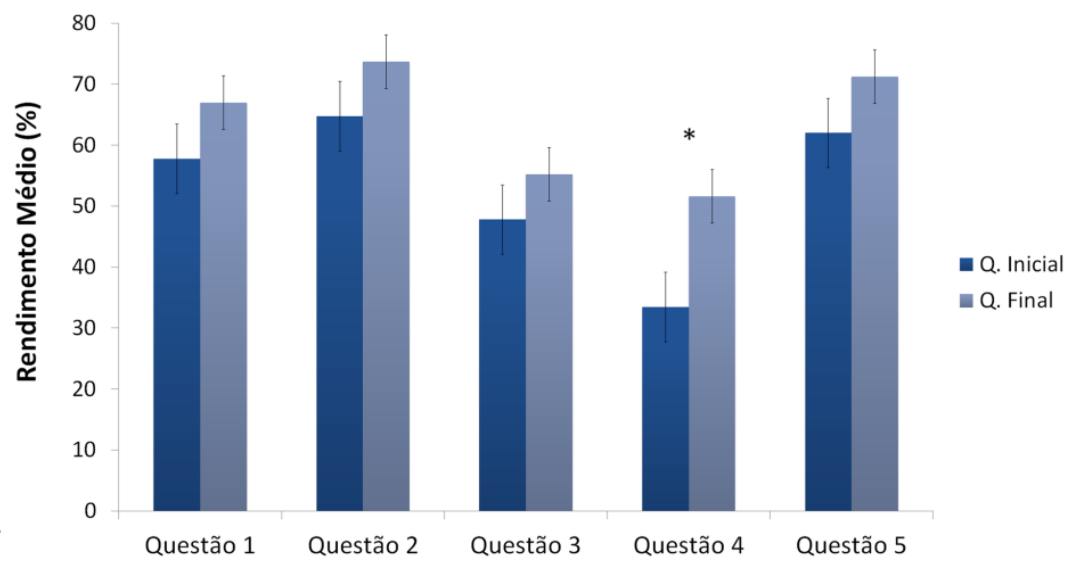

C.

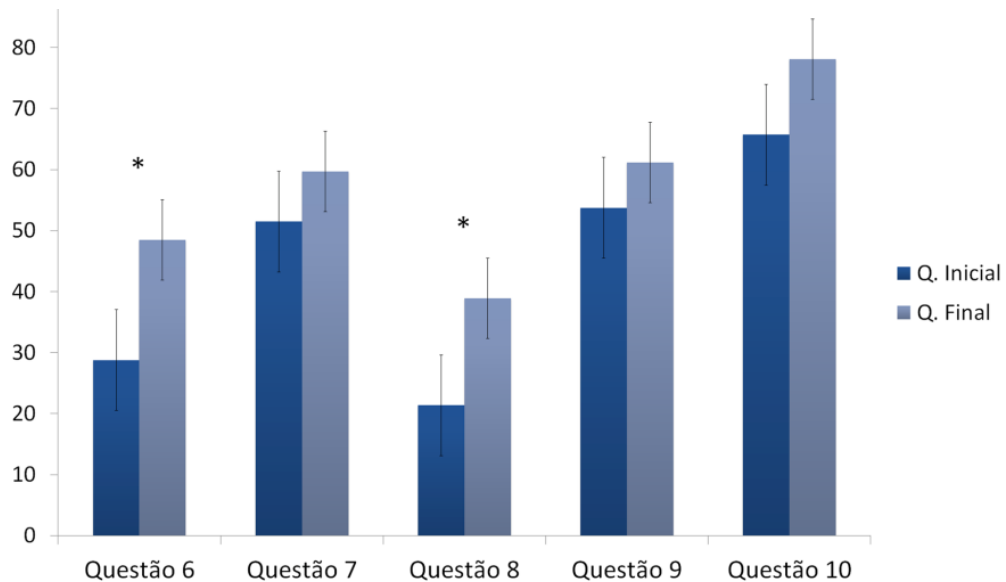

Figura 1. Avaliação geral com base no questionário diagnóstico. A) Comparação entre as turmas; B) Comparação de acertos/questão de biologia vegetal; C) Comparação de acertos/questão de biotecnologia vegetal. Asteriscos em A representam a intensidade da diferença entre os rendimentos de cada turma pelo teste $t$ pareado $(p<0,05)$. Asteriscos em $\mathrm{B}$ e $\mathrm{C}$ indicam diferença significativa entre o desempenho dos alunos pelo teste de McNemar $(\mathrm{p}<0,05)$ 


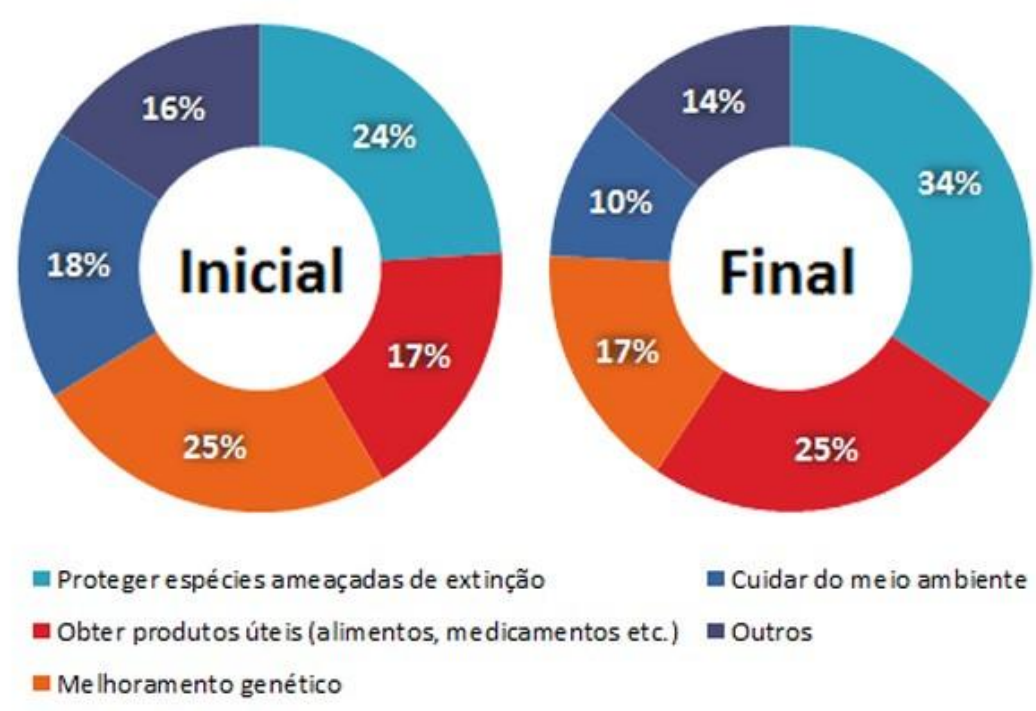

Figura 2. Frequência de respostas da questão discursiva nas categorias definidas.

O projeto foi eficaz no reforço dos conceitos sobre o "núcleo da célula eucariótica", presente no currículo mínimo da PCNEM. Entretanto, o baixo rendimento inicial na questão relacionada a este tema denota desconhecimento das estruturas celulares, sendo preocupante que alunos de turmas concluintes, prestes a ingressar no ensino superior, não tenham adquirido as habilidades propostas no PCNEM de Biologia.

Neste contexto, embora não se trate de ciência abstrata, a biologia vegetal tem se mostrado alvo de dificuldade de aprendizado, com consequente descaso por parte dos alunos. Seu aprendizado depende de uma abordagem prática e visual que, com raras exceções, não é realizada na escola pública, sendo este conteúdo considerado complexo e subjetivo, pelos alunos (NOGUEIRA, 1997). Além disso, o vocabulário técnico representa dificuldade extra (KRASILCHIK, 2005). Agravando este quadro, os professores demonstram dificuldade em associar o conteúdo didático ao universo de saberes do aluno (SANTOS, 2015).

As atividades práticas e experimentais são consideradas a forma mais objetiva de demonstrar os fenômenos biológicos, mas dependem de estrutura laboratorial raramente disponível nas escolas públicas, cronicamente afetadas pelo problema sócio-econômico do país. Entretanto, mesmo sem aulas práticas tradicionais, concluiu-se neste trabalho, que a introdução de novos conceitos sobre a "totipotência" e sobre a "micropropagação" foram compreendidos pelos alunos, apesar de desconhecidos até então, e os dados obtidos indicam que cerca de um quinto dos alunos participantes assimilou estes conteúdos por meio da metodologia utilizada. Muitas vezes, elementos externos à esfera escolar podem favorecer a transmissão de conhecimentos. Em muitos estabelecimentos, as atividades complementares ficam limitadas a organizações não-governamentais (ONG) e/ou projetos educacionais vinculados às Universidades. Infelizmente, a aplicação de métodos alternativos, como imagens, vídeos e a realização de visitas técnicas para o aprendizado, não são práticas comuns na rede pública, pois demandam um tempo adicional de preparação e de aplicação, não previstos na carga horária do professor que, na maior parte das vezes, também não conta com o apoio dos colegas ou da escola (PEREIRA et al., 2012).

\section{Considerações Finais}

O presente trabalho contribuiu para estabelecer uma reflexão junto aos alunos do ensino médio da rede pública, sobre a importância de se conservar a biodiversidade vegetal, utilizando-se técnicas biotecnológicas.

Foram observados resultados efetivos na introdução de novos conteúdos de biotecnologia e sua aplicação na conservação da biodiversidade vegetal, com a metodologia proposta.

O interesse demonstrado nas palestras e documentários, ministradas pelos alunos da UERJ, indicaram que o uso de uma metodologia dinâmica e a atualização dos professores podem favorecer a aplicação de abordagens metodológicas diferentes para o ensino de Biologia.

\section{Agradecimentos}

Ao Departamento de Extensão da Universidade do Estado do Rio de Janeiro pela concessão de uma bolsa e à Fundação de Amparo à Pesquisa do Rio de Janeiro e à Coordenação de Aperfeiçoamento de Pessoal de Nível Superior e ao Conselho Nacional de Desenvolvimento Científico e Tecnológico, a concessão de auxílios financeiros. Aos Professores Adriano Caldeira de Araujo (in memorium) e Antônio Carlos de Freitas do Departamento de Biofísica e Biometria IBRAG/UERJ, pelas análises estatísticas, à Coordenação de Áreas do Conhecimento/ Superintendência Pedagógica (SEEDUC) 
e à Direção do Colégio Estadual João Alfredo por autorizarem a publicação dos resultados (Proc. E03/015/1494/16).

\section{Contribuição de cada autor}

I.B.S, execução do projeto, descrição das intervenções realizadas e tabulação dos dados; B.O.S. e J.A.P, execução das atividades no colégio; R.O.G, execução das atividades nos laboratórios da universidade; C.R.S, planejamento e coordenação das atividades no colégio; R.F.G, planejamento, coordenação geral do projeto e redação/edição do artigo.

\section{Referências}

BRASIL, Ministério da Educação e Cultura, Secretaria de Educação Média e Tecnológica. Orientações Educacionais Complementares aos Parâmetros Curriculares Nacionais - PCN+ Ensino Médio. Brasília: MEC/SEMTEC. 2002. 141 p. Disponível em: <http://portal.mec.gov.br/seb/arquivos/pdf/CienciasNatur eza.pdf $>$. Acesso em 27 out. 2015.

BRASIL, Ministério da Educação e Cultura, Secretaria de Educação Média e Tecnológica. Parâmetros Curriculares Nacionais para o Ensino Médio. Parte III - Ciências da Natureza, Matemática e suas Tecnologias. Brasília: MEC/SEMTEC. 2013. Disponível em: $\quad\langle$ http://portal.mec.gov.br/seb/arquivos/pdf/ ciencian.pdf $>$. Acesso em: 20 fev. 2015.

CANHOTO, J. M. Biotecnologia vegetal da clonagem de plantas à transformação genética. 1. ed., Coimbra: Imprensa da Universidade de Coimbra. 407 p., 2010. 407 p.

FAJARDO, V. MEC amplia currículo alternativo para tirar ensino médio público da crise. G1, [S. 1.], mai. 2012. Disponível em: <http://g1.globo.com/educacao/ noticia/2012/05/mec-amplia-curriculo-alternativo-para-

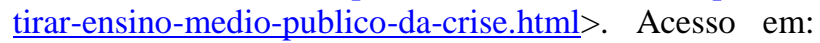
05 abr. 2015.

FREITAS, M. E. M.; MIRANDA, M.; FERNANDES, H. L.; CINQUETTI, H. C. S.; BENEDITTI, R.; COSTA, E. Desenvolvimento e aplicação de kits educativos tridimensionais de célula animal e vegetal. Ciências em Foco, v.1, n.2, p. 1-11, 2009.

KRASILCHIK, M. Prática de ensino de Biologia. 4. ed. São Paulo: Editora da Universidade de São Paulo, 2005. $197 \mathrm{p}$.

MACHADO, M. M. B. Temas Meio ambiente, Sustentabilidade e Educação ambiental no ensino de Biologia: um estudo sobre as práticas dos professores do Ensino Médio de Sapucaia do Sul, RS. Dissertação de Mestrado. Universidade Federal do Rio Grande do Sul. Rio Grande do Sul, 2014.

METZGER, J. P.; CASATTI, L. From diagnosis to conservation: the state of the art of biodiversity conservation in the BIOTA/FAPESP program. Biota Neotropica, v.6, n.2, p.1-23, 2006.

NOGUEIRA, A. C. O. Cartilha em quadrinhos: um recurso dinâmico para se ensinar Botânica. In: $6^{\circ}$ Encontro Perspectivas do Ensino de Biologia,São Paulo, Coletânea... São Paulo: USP, 1997, p. 135-145.

PEDRANCINI, V. D.; CORAZZA-NUNES, M. J.; GALUCH, M. T. B.; MOREIRA, A. L. O. R.; RIBEIRO, A. C. Ensino e aprendizagem de Biologia no ensino médio e a apropriação do saber científico e biotecnológico. Revista Electrónica de Enseñanza de las Ciências, v.6, n.2, p.299-309, 2007.

PEREIRA, M. G.; BARBOSA, A. T.; ROCHA, G. S. D. C.; NASCIMENTO, C. V. C.; NECO, E. C. Modalidades didáticas utilizadas no Ensino de Biologia na educação básica e no ensino superior. In: X Jornadas Nacionales y V Congreso Internacional de Enseñanza de la Biología, 2012, Córdoba. Memorias... p.590-594. Córdoba, Argentina: ADBIA, 2012.

QUINTINO, C. A.; ROSA, M. I. F. P. S. Investigando relações entre currículo integrado e interdisciplinaridade numa história de formação continuada de professores do ensino médio da área de ciências. In: Encontro Nacional de Pesquisa em Educação em Ciências, 5, 2005, Bauru. Atas... São Paulo: ABRAPEC, n. 5, 2005. 13 p. Disponível em: < http://abrapecnet.org.br/atas_enpec/ venpec/conteudo/index.htm > Acesso em: 27 out. 2017.

RIBEIRO, R. A.; RODRIGUES, F. M. Genética da conservação em espécies vegetais do cerrado. Revista de Ciências Médicas e Biológicas, v.5, n.3, p.253-260, 2006.

ROCHA SILVA, C.; CHRISTO GOBBI, B., ADALGISA SIMÃO, A. O uso da análise de conteúdo como uma ferramenta para a pesquisa qualitativa: descrição e aplicação do método. Organizações Rurais \& Agroindustriais, v. 7, n. 1, p. 70-81, 2005.

SANO, T. P. Livros Didáticos. In: SANTOS, D.Y.A.C., CECCANTINI, G. (Orgs.). Proposta para o ensino de botânica: manual do curso para atualização de professores da rede pública de ensino. São Paulo: Universidade de São Paulo, Instituto de Biociências, 2004, p.43-44.

SANTOS, W. A. Uma reflexão necessária sobre a profissão docente no Brasil, a partir dos cinco tipos de desvalorização do professor. Sapere Aude - Revista de Filosofia, v.6, n.11, p.349-358, 2015.

SIEGEL, S., CASTELLAN JÚNIOR, N. J. Estatística não-paramétrica para ciências do comportamento. 2 . ed. Porto Alegre: Artmed. 2006. 448 p.

SILVA, A. B. V.; MORAES, M. G. Jogos pedagógicos como estratégia no ensino de morfologia vegetal. Enciclopédia Biosfera, v.7, n.13, p.1642-1652, 2011.

SILVA, J. N.; GHILARDI-LOPES, N. P. Botânica no ensino fundamental: diagnósticos de dificuldades no ensino e da percepção e representação da biodiversidade vegetal por estudantes. Revista Eletrônica de Enseñanza de las Ciencias, v.13, n.2, p.115-136, 2014. 
XAVIER, M.C.F., SÁ-FREIRE, A., MORAES, M.O.A. Nova (moderna) Biologia e a genética nos livros didáticos de biologia no Ensino Médio. Ciência \& Educação, v.12, n.3, p.275-289, 2006.

$* * *$

Como citar este artigo:

SOUSA, I. B.; SOARES, B. O.; PETTINELLI, J. A.; GARCIA, R.; SILVA, C. R.; GAGLIARDI, R. F. Conservação in vitro da biodiversidade vegetal: abordagem no ensino médio. Revista Brasileira de Extensão Universitária, v. 9, n. 1, p. 47-56, 2018. Disponível em: < https://periodicos.uffs.edu.br/ index.php/RBEU/article/view/6838/pdf $>$ 


\section{Anexo 1}

\section{Questionário Geral}

Unidade escolar:

Número na chamada: Turma: Data:

\section{Atenção! Somente uma questão está correta.}

1- Qual é a definição de Biodiversidade?

( ) É o número total de espécies e variedades de seres vivos que existem no planeta Terra.

( ) Corresponde somente ao número total de animais terrestres.

( ) Corresponde somente as espécies de plantas da Mata Atlântica.

( ) É a diversidade de organismos presentes em $1 \mathrm{~g}$ de terra.

( ) Minerais, animais e vegetais presentes em qualquer ecossistema.

2- Tanto o Reino Vegetal quanto o Animal são formados por organismos pluricelulares. Com relação a estes reinos, podemos afirmar que:

( ) Ambos os Reinos são compostos por seres vivos.

( ) Apenas o Reino Animal é formado de seres vivos.

( ) Somente os animais respiram.

( ) Todos os organismos dos dois Reinos produzem seu próprio alimento.

( ) Não deveria haver a separação em dois reinos, visto que ambos são muito semelhantes.

3- Sobre o núcleo das células eucarióticas, podemos afirmar:

( ) O material genético fica disperso no citoplasma.

( ) O núcleo contém o material genético.

( ) Células eucarióticas não apresentam núcleo ou material genético.

( ) O núcleo não possui comunicação com o resto da célula.

( ) A cromatina está presente tanto no citoplasma quanto no núcleo da célula.

4- Com relação à célula vegetal, podemos afirmar que:

( ) Não possui vacúolo.

( ) Somente os vírus possuem.

( ) Possui parede celular.

( ) É a parte não viva de um organismo.

( ) Não apresenta núcleo ou material genético.

5- A fotossíntese é um processo que:

( ) todos os seres vivos conseguem realizar.

( ) necessita de luz solar, mas não de água.

( ) induz o consumo de oxigênio e liberação de gás carbônico.

( ) não necessita de luz.

( ) permite que as plantas produzam o seu próprio alimento.

6- Totipotência é a capacidade de uma única célula se dividir e produzir outros tipos celulares. Podemos dizer que:
( ) As células totipotentes dos animais são chamadas de células-tronco.

( ) Nos animais qualquer célula viva pode ser considerada totipotente.

( ) As plantas só se multiplicam por meio das sementes.

( ) As células totipotentes originadas de folhas não formam células de raiz.

( ) Qualquer célula viva pode ser considerada totipotente.

7- A clonagem é um processo natural ou artificial de produção de um ser vivo geneticamente idêntico a outro. Com relação à clonagem:

( ) O Homem ainda não conseguiu produzir artificialmente clones de plantas.

( ) Este processo foi alcançado artificialmente apenas com animais.

( ) Um exemplo de clonagem natural é a reprodução de microorganismos por bipartição.

( ) Não é usada na produção de plantas alimentares.

( ) Não é possível fazer clonagem artificialmente.

8- O que você entende por micropropagação?

( ) É a produção rápida de milhares de clones de um animal.

( ) Técnica utilizada para fornecer um número elevado de mudas de plantas.

( ) Técnica utilizada para propagar qualquer tipo de ser vivo.

( ) Método artificial de propagação vegetativa no campo

( ) Não sei.

9- A cultura de tecidos vegetais é uma técnica que permite a multiplicação de plantas com características agronômicas de interesse. A técnica se baseia na descontaminação e inoculação em meios de cultura, de pequenos pedaços do vegetal. Com relação a esta técnica:

( ) Não pode ser usado para produzir plantas ameaçadas de extinção.

( ) É uma excelente ferramenta para a obtenção de plantas.

( ) Não pode ser usado para melhoramento genético de plantas.

( ) Esta técnica ainda não é realizada no Brasil.

( ) Nunca ouvi este termo ou não sei o que significa.

10- A Biotecnologia Vegetal se baseia na cultura de tecidos (CTV) e envolve a manipulação de plantas para obter produtos úteis. Como a biotecnologia pode ajudar também na proteção ao meio ambiente?

( ) A CTV é usada na conservação ao multiplicar espécies ameaçadas de extinção.

( ) Não ajuda, pois as plantas cultivadas in vitro não sobrevivem no ambiente.

( ) Não é possível cultivar plantas ameaçadas in vitro.

( ) Através do melhoramento de plantas.

( ) Não sei.

11- Você saberia explicar qual a importância da Biotecnologia Vegetal para a humanidade? Justifique.

( ) Sim.

( ) Não. 